\title{
Liderança feminina na gestão pública municipal - desafios e aprendizados de mulheres prefeitas
}

\author{
Feminine leadership in municipal public management- \\ Challenges and learning of female mayor
}

Luciana Scherer

Louise De Lira Roedel Botelho

Recibido: 01/05/2017

Aceptado: $17 / 06 / 2018$

\section{RESUMO}

Ao longo dos tempos as mulheres têm perpassado por transformações quanto a reconfiguração de seu papel na sociedade. Com a entrada da mulher no mercado de trabalho, configuram-se também novas lideranças e novas formas de exercer poder. Elas passaram a ocupar cargos e funções até então desempenhadas exclusivamente por homens trazendo um novo dinamismo às organizações públicas. A evolução nos modelos gerenciais públicos tem permitido que um número cada vez maior de mulheres ocupe espaços na política e na gerência de órgãos públicos, embora o número de mulheres atuantes na política venha aumentando ao longo dos últimos anos ainda é subrepresentado se comparado ao número de homens. O objetivo principal deste trabalho é compreender as trajetórias de 4 mulheres que se tornaram prefeitas na no estado do Rio Grande do Sul através das experiências vividas das investigadas no exercício de suas funções gerenciais e políticas no setor público.

Palabras clave: gestão feminina; liderança feminine; carreira feminine; prefeitas.

\begin{abstract}
Throughout the ages, women have undergone transformations regarding the reconfiguration of their role in society. With the entry of women into the labor market, new leaderships and new ways of exercising power are also set up. They now occupy positions and functions previously performed exclusively by men bringing a new dynamism to public organizations. The evolution in public management models has allowed an increasing number of women to occupy spaces in the politics and in the management of public organs, although the number of women in politics has increased in the last years is still underrepresented when compared to the Number of men. The main objective of this work is to understand the trajectories of 4 women who became mayor in the state of Rio Grande do Sul through the experiences of those investigated in the exercise of their managerial and political functions in the public sector.
\end{abstract}

Keywords: women’s management; women’s leadership; female career; female mayor

Luciana Scherer es profesora de Turismo en la Universidade Regional Integrada do Alto Uruguai e das Missões (Brasil). Correo electrónico: lucianascherer@yahoo.com.br. ID: https://orcid.org/0000-0002-2774$\underline{7994}$

Louise De Lira Roedel Botelho es profesora de Educación en la Universidadade Federal da Fronteira Sul (Cerro Largo, Brasil). Correo electrónico: louisebotelho@uffs.edu.br.

Cómo citar este artículo: Scherer, L. y Botelho, L.L. R (2018). Liderança feminina na gestão pública municipal - desafios e aprendizados de mulheres prefeitas. Atlánticas. Revista Internacional de Estudios Feministas, 3 (1), 224-248 doi: http:/ /dx.doi.org/10.17979/arief.2018.3.1.2043 


\section{INTRODUÇÃO}

A trajetória das mulheres na sociedade está cercada por diferentes transformações. Essas transformações geraram resultados no modo de vida feminino, sendo reflexos das construções sociais produzidas ao longo dos tempos. A sociedade, talvez por questões de garantir a própria sobrevivência da espécie humana, agregou às mulheres o papel de cuidadoras no ambiente familiar, e essa função social das mulheres esteve associada por muito tempo à função materna. À medida que a sociedade vai se transformando de uma era agrária para industrial, a função social das mulheres vai se adequando aos novos modelos. Surge a emancipação feminina, ou seja, uma busca pela igualdade de gêneros, nas relações da esfera do trabalho. Todo esse novo contexto acaba por modificar as formas como homens e mulheres condicionam suas competências a serviço da sociedade e não apenas da família. A partir disso, as mulheres passam a pertencer à esfera pública do trabalho (FLETCHER, 2006). Como resultado elas passaram adquirir direitos e autonomia financeira e a engendrar no mundo formal do trabalho, que durante muito tempo foi percebido socialmente como um universo de predomínio masculino.

Nas transformações no papel das mulheres na sociedade, a gestão pública talvez exerça um caso peculiar, já que os processos de seleção eleitorais trazem para esse cenário da participação feminina contornos ainda não suficientemente investigados. A evolução nos modelos gerenciais públicos tem permitido que um número cada vez maior de mulheres ocupe espaços na política e na gerência de órgãos públicos, tornando-se mais propensas a assumir cargos de maior responsabilidade e exigência técnica por seus méritos, seja por indicação ou eleição, contudo, ainda muito aquém da participação masculina (SOUZA, SIQUEIRA, BINOTTO, 2011). Salienta-se que embora o número de mulheres atuantes na política venha aumentando ao longo dos últimos anos ainda é subrepresentado se comparado ao número de homens que exercem cargos políticos, podendo-se afirmar que o cenário político brasileiro ainda é marcado por traços de coronelismo masculino.

Referente à atuação em cargos políticos, segundo os dados do Tribunal Superior Eleitoral - TSE, embora as mulheres representem cerca de 52\% do eleitorado brasileiro em 2012, essa mesma proporção não é retratada na ocupação dos cargos políticos, já que $11,92 \%$ do total de municípios brasileiros elegeu, para a 
gestão 2013-2016, mulheres para estarem a frente das respectivas prefeituras, ou seja, 664 prefeitas (TSE, 2016). Em termos históricos, destaca-se que o caminhar de uma mulher ocupando o cargo de prefeita no Brasil teve o seu primeiro passo em 1928, com a eleição de Alzira Soriano, eleita aos 32 anos, para a prefeitura de Lajes, cidade do interior do Rio Grande do Norte, quando as mulheres nem sequer podiam votar. Em 2012, no estado do Rio Grande do Sul, foram eleitas 35 prefeitas, perfazendo um percentual de 7,04\%.

O objetivo principal deste trabalho é compreender trajetórias de 4 mulheres que se tornaram prefeitas no estado do Rio Grande do Sul, no Brasil através das experiências vividas das investigadas no exercício de suas funções gerenciais e políticas no setor público.

Este estudo está divido em três partes, além dessa introdução e das considerações finais. A primeira apresenta os delineamentos metodológicos, as opções e posturas de pesquisa, bem como os instrumentos e técnicas como forma de conhecer a realidade a ser investigada. A segunda traz as discussões teórico-epistemológicos sobre as mulheres e a representação política, através de apresentação de teorias e estudos já realizados acerca do tema. Na sequência são apresentadas as realidades das prefeitas, com suas particularidades, desafios, aprendizados e superações nas respectivas carreiras.

\section{PROCEDIMIENTOS METODOLÓGICOS}

Este estudo utiliza o paradigma humanista de pesquisa (Hughes, 1980) o qual o designa como um estudo qualitativo de cunho fenomenológico (Roesch, 1996; Minayo, 1994), já que se pretende compreender a trajetória das prefeitas comum olhar subjetivo da realidade (Hughes, 1980). Trata-se também de uma pesquisa exploratória, com uma abordagem pautada tanto em esforços epistemológicos no sentido da busca de dados disponíveis e estudos já realizados - e ontológicos - no sentido de um esforço de busca de conhecimento a partir da realidade do próprio "objeto" pesquisado.

Como procedimento de coleta de dados foi utilizado o modelo de entrevista em profundidade de Seidman (1998). Foram entrevistadas 4 prefeitas de municípios do Rio Grande do Sul. O instrumento utilizado foi a realização de entrevistas em profundidade com o apoio de um questionário semiestruturado. 
Conforme Gil (1991) o questionário é um instrumento de coleta de dados constituído por uma série ordenada de perguntas e intervenções.

Para a validação do questionário, foi aplicado um piloto a uma mulher que já havia sido prefeita em outro município que não foi objeto deste estudo. Com base nas sugestões da respondente voluntária, ocorreram ajustes, a partir daí o questionário final foi elaborado.

O questionário foi organizado para abordar três perspectivas acerca da vida e da atuação da prefeita. A primeira perspectiva, sobre a trajetória pessoal e profissional teve como objetivo buscar elementos sobre a vida da prefeita antes de ser prefeita: relatos sobre a infância, sobre a família, sobre a atuação pessoal e profissional até o momento em que as investigadas se tornaram prefeitas. A segunda perspectiva trabalhou com foco na formação da identidade política das investigadas. Assim, buscou-se investigar os elementos condutores da formação da identidade política das prefeitas. Para tanto utilizou-se o arcabouço conceitual de Blay (2015). Blay (2015) realizou em 1978 um estudo pioneiro sobre as prefeitas baianas, sendo esse posteriormente corroborado por outras pesquisadoras, entre as quais: Claudia Barbosa (2010) em estudo sobre prefeitas baianas, Glória Rabay (2013) em trabalho apoiado pelo CNPq sobre a representação política da mulher na Paraíba e Dayanny Rodrigues (2016) em trabalhos realizados também sobre as prefeitas paraibanas. Por último, a terceira perspectiva relativa à carreira, tratou-se de conhecer alguns tópicos influenciadores da carreira feminina já conhecidos na literatura (Bruschini, 2000; Botelho, 2006; 2008; Moraes, 2008) como: a influência e a relação de marido e filhos (as) na carreira política das entrevistadas; a identificação das recompensas e dificuldades, mudanças na vida pessoal e profissional; aprendizagem e satisfação com a trajetória política. A coleta de dados ocorreu no período de outubro de 2016 a dezembro de 2016, período em que as prefeitas já se encontram com uma experiência mínima próxima aos quatro anos de mandato. Todas as entrevistas foram realizadas com agendamento prévio e no gabinete das entrevistadas, que foram gravadas e posteriormente transcritas.

Para que se analise os dados deste estudo, com base na gravação e transcrição da entrevista foram criadas categorias analíticas, para assim poder-se construir o texto final desta pesquisa.

Para criação de categorias analíticas utilizou-se o modelo de Miles e Huberman (1994), desta forma os resultados encontrados foram alocados em três 
momentos distintos:

(a) Redução de dados: processo que permite a seleção, o foco, a simplificação, a abstração e a transformação dos dados coletados com o objetivo de obter algumas conclusões;

(b) Dispositivos visuais: são construções organizadas e condensadas de informações que ajudam no entendimento do estudo, proporcionando um encadeamento de ideias à medida que os dados vão sendo processados;

(c) Desenhos e verificações conclusivos: permite a organização de informação em séries diferentes, a criação de uma matriz de categorias, tabulação da frequência de diferentes eventos, dessa forma, as conclusões surgirão da manipulação de dados a partir do momento em que se contrapõe os dados de entrevistados diferentes.

Ressalta-se que a postura metodologia desse estudo de casos é realizá-lo com cuidado, especialmente em relação às generalizações, ou seja, aqui a intenção metodológica é realmente conhecer os casos estudados, para, a partir daí propiciar a possibilidade, de futuramente realizarem-se estudos mais generalizáveis sobre o fenômeno em questão.

\section{MULHERES E PARTICIPAÇÃO POLÍTICA}

A condição milenar da mulher na sociedade influencia a caminhada e o papel da mulher na atualidade. A crença quase natural em nossa sociedade, de que "o homem é superior à mulher, acaba legitimando a discriminação" (Moraes, 2004, p. 22). A história da mulher também é de submissão ao homem, sendo uma construção social e cultural repleta de tensões e posicionamentos onde as diferenças entre homens e mulheres são enfatizadas e observadas em diferentes campos, que se apresentam como esquemas de pensamento, de aplicação universal, e se registram como diferenças de natureza, inscritas na objetividade (Bourdieu, 2011). As diferenças biológicas são transferidas para o campo social, sendo assim naturalizadas. Nas esferas de representação política da sociedade, esse cenário também se manifesta. Dados referentes à participação das mulheres em esferas do governo mostram que elas continuam sendo subrepresentadas, o que também pode ser reflexo de uma desigualdade nos campos cultural, social e econômico. 
Para contextualizar essa afirmação, buscam-se os dados sobre a relação do percentual de mulheres eleitas no Brasil - 11,92\%, e no Rio Grande do Sul 7,04\% em 2012, para a gestão 2013-2016. Com esses dados, é possível inferir que o Brasil ainda se encontra na retaguarda mundial no que se refere ao empoderamento feminino nos indicadores de participação da mulher na política (Alves, 2007), e, portanto, estudar os cenários que se encontra acerca desse fenômeno auxilia no conhecimento e na capacidade de atuação das mulheres na política.

Em estudos sobre a participação da mulher na política brasileira, destacam-se quatro momentos e acontecimentos importantes: a conquista do voto feminino em 1932, a emergência do movimento feminista da década de 70, a constituição de 1988 e as cotas eleitorais para mulheres.

A luta pelo voto feminino no Brasil iniciou-se nas primeiras décadas do século XIX quando as mulheres começaram a reclamar este direito, contrapondo-se à mentalidade vigente na sociedade da época que considerava a natureza feminina incompatível com as atividades políticas. Em 1932, o então presidente Getúlio Vargas promulga o Decreto $\mathrm{n}^{\circ} 21.076$, aprovando o voto feminino às mulheres casadas, desde que tivessem autorização dos maridos, e a algumas solteiras ou viúvas, desde que tivessem renda própria o direito de votar e serem eleitas.

O movimento feminista dos anos 1970, embora influenciado pelas experiências europeias e norte-americanas, foi marcado pela contestação à ordem política instituída no Brasil da época. Para Saffioti (1976) o movimento feminista brasileiro desempenhou funções de uma força social construtiva, e dessa forma, a emergência do feminismo como movimento social criou o alicerce para a legitimação da condição feminina (Bruschini, 2000).

Em relação a Constituição de 1988, essa assegurou a igualdade em direitos e obrigações para mulheres e homens e a igualdade na sociedade conjugal, bem como a criação de novos direitos, como planejamento familiar, proteção contra a violência no âmbito das relações familiares; ampliação da noção de família; não discriminação dos filhos havidos fora do casamento; licença paternidade; creches e pré-escolas; proteção ao mercado de trabalho da mulher, dentre outros. 
Sobre as cotas eleitorais para mulheres, pode-se destacar dois acontecimentos, a Lei 9100/95 e a Lei 9504/97. A primeira lei prescrevia a exigência do registro de no mínimo $20 \%$ de candidaturas femininas por cada partido ou coligação. No mesmo ano, a então Deputada Federal Marta Suplicy, apoiada por mais 26 deputadas, elaborou o Projeto de Lei 783, que cominou na revogação do art. 92 do Código Eleitoral, aumentando o percentual mínimo para 30\%, entrando em vigor a segunda lei acima citada (Vaz, 2008).

A referida lei não está livre de ressalva, embora seja um avanço. Para Blay (2002), houve pouco debate com a sociedade para implantação da lei, especialmente com o movimento de mulheres, além de serem rejeitadas propostas que criariam melhores condições de competição por parte das mulheres. Porém, tornar mais visível a questão a pouca representação política da mulher é um ponto positivo da lei (Brabo, 2003), pois trouxe à tona muitas reflexões, discussões e questionamentos sobre a não participação e até mesmo à exclusão da mulher nas esferas de poder.

Ainda, quando se analisa as candidaturas ao cargo de Prefeito, tem-se que nas eleições de 2012, segundo dados do Tribunal Superior Eleitoral (TSE, 2016), que as mulheres representaram apenas $13,4 \%$ das candidaturas. Essa situação pode ser explicada pelo fato de que a "lei de cotas" não contempla o poder executivo, tendo em vista que está limitada a cargos escolhidos por sistema proporcional. Mesmo com uma participação ainda pequena, é importante considerar o papel de tais agentes nos estudos sobre a atuação nos cenários políticos, sociais, culturais, ligando essas percepções ao universo feminino e ao desenvolvimento das regiões. Partindo da análise dos dados eleitorais e das discussões incitadas, sente-se a necessidade de compreender as mulheres enquanto protagonistas em um processo de empoderamento social e político.

Blay (2015), em seu estudo sobre as prefeitas no Brasil, concluiu que algumas características e situações aglutinam-se mutuamente, ou seja, há algumas características como relações familiares, personalidades e forma de ingresso na vida política definiram, para essa autora, a possibilidade de uma classificação geral baseada em três categorias: a Prefeita Coronel, a Prefeita Esposa e a Prefeita por Iniciativa Própria. 
A Prefeita Coronel é aquela que, principalmente - mas não necessariamente - na ausência de um homem, assume a liderança da família, a direção dos negócios, do grupo político e da clientela, através da utilização de velhas práticas clientelísticas como as do "mandonismo". Em sua maioria pertencente às oligarquias locais, assim como os homens, é socializada para assumir a direção política do grupo familiar quando se faz necessário. As Prefeitas Coronel, assumem a posição de líder na família, podendo essa posição ser obtida perante a sua família de origem como a estabelecida pelo casamento. Ao incorporarem essa liderança é possível que utilizem alguns traços comportamentais típicos masculinos e muitas vezes precisam convencer seus pares sobre a sua capacidade. Assim, a luta pela liderança começa em casa, no seu ambiente familiar.

Esses traços comportamentais masculinos são definidos em termos de controle, desempenho e intenções instrumentais, enquanto a feminilidade se aproxima a características mais "softs" como as atitudes de colaboração e suporte (Fournier, Smith, 2006). Loden (1988) apresenta três características que elucidam o contexto do masculinismo, quais sejam: a competição, a habilidade de pensar analiticamente ou estrategicamente e a positividade ou comportamento agressivo. Segundo a autora, a relação de negócio do masculinismo e até a sua relação sobre a vida são representadas em termos de luta frequentemente competitiva onde há apenas vencedores e perdedores, onde a meta dominante é vencer ou triunfar sobre seus adversários. Sobre a habilidade de pensar analiticamente ou estrategicamente, o masculinismo valoriza o controle através de cálculos meticulosos e a capacidade organizativa de desenvolver planos e estratégias. Já com relação à positividade, o masculinismo preza pelo respeito aos ocupantes das posições hierárquicas mais altas, bem como um comportamento agressivo aos que estão nas posições inferiores.

A prefeita esposa é aquela que assume as funções do marido na política, em decorrência de algum impedimento de ordem legal, ou com o objetivo de continuar no controle do poder. Ainda, a imagem adquirida como "esposa de político", por meio de atividades sociais ou assistencialistas, garante a constituição de uma base eleitoral que é sabiamente aproveitada. Assim, exercer o cargo é em verdade uma delegação do marido e, portanto, pode ocorrer que, quando é necessário tomar uma decisão importante para o município se consulta ao marido (Blay, 2015). 
Por fim, a "prefeita por iniciativa própria", seria aquela que por suas próprias convicções e liderança construiu capital político suficiente para se eleger. Desse modo, esse terceiro grupo se distinguiria dos dois primeiros.

Além da tipologia apresentada por Blay (2015) outro importante conceito emerge na discussão deste trabalho, o de capital político desenvolvido por Bourdieu (1980; 1996). Esse conceito basicamente indica o reconhecimento social que permite que alguns indivíduos, mais do que outros, sejam aceitos como atores políticos e, portanto, capazes de agir politicamente.

O capital político é uma forma de capital simbólico, cuja eficácia está ligada à universalidade do reconhecimento que ele recebe, ou seja, ele permite alguma autoridade a alguém. O capital político é tido então, como uma espécie de capital simbólico: o reconhecimento da legitimidade daquele indivíduo para agir na política (Bourdieu, 1980). Afirma ainda que o "capital político é que se adquire nos aparelhos de sindicatos e dos partidos transmite-se através de redes de relações familiares que levam à constituição de verdadeiras dinastias políticas" (Bourdieu, 1996, p.30).

O que muda se compararmos o tipo de prefeita, segundo a classificação proposta, é a forma como a mesma constrói e faz legitimar o seu capital político, ora pela atuação da família, na ausência de um homem para comandar os negócios e a política; ora pela atuação como esposa de um político, ou até mesmo pela sua atuação de forma independente na sociedade e nas esferas políticas. Nota-se que, a noção de dinastia política acima colocada por Bourdieu parece bastante ligada à forma de construção de capital político das Prefeitas Coronel e das Prefeitas Esposa, as quais já possuem um capital simbólico herdado pela atuação da família e/ou marido.

Bourdieu (1986) elabora o desafio de desenvolver a questão da importância conexão entre grupo e indivíduo representante e aborda a necessidade de reflexão sobre o poder que os líderes políticos possuem ao agir e ao comunicarse em nome dos representados. Um líder deve democratizar seu interesse próprio objetivando parecer ser o interesse dos liderados, e para isso existe um conjunto de técnicas de oratória, de construção textual e de aparência.

Através dos aspectos quantitativos da participação política feminina é possível 
encontrar respostas sobre os mecanismos de dominação que, ainda hoje, mantém a baixa participação das mulheres nas instâncias representativas da política e do poder (Barbosa; Cavalcanti, 2010).

Prevalece ainda na sociedade uma visão reducionista, que adequa as "vontades femininas" a falta de interesse e envolvimento com os assuntos políticos. $\mathrm{O}$ fato é que é necessário buscar as causas, conhecer a trajetória, o perfil, as aprendizagens e os desafios e superações vividos pelas mulheres que desenharam suas carreiras profissionais na vida pública. Estudar essas mulheres é reconhecer que ser mulher em um ambiente tradicionalmente marcado pela cultura masculina de poder pode se mostrar como um cenário de intensos desafios e aprendizagens.

\section{OS DESAFIOS E AS SUPERAÇÕES NO PAPEL DE PREFEITA - APRENDIZADOS PARA A VIDA EM ESFERA PÚBLICA E PRIVADA}

A primeira constatação destacada na pesquisa diz respeito a tipologia embasada no arcabouço teórico proposto por Blay (2015). Apesar de considerarse que classificações muitas vezes desconsideram aspectos individuais significativos, nas falas de apresentação das prefeitas é possível identificar as características dominantes que permitem utilizar a proposição da autora. Dentre as entrevistadas, não é possível considerar alguma Prefeita Coronel, pois todas são casadas e o marido aparece como figura importante e atuante em suas vidas. Duas foram identificadas como Prefeita por Iniciativa Própria - aquela que não possui tradição de ocupação de cargo político nem na família de origem, nem na família de matrimônio e identifica-se como a decisão de candidatar-se a prefeita como sua própria. Outras duas foram identificadas como Prefeita Esposa - aquela que assume o desafio de um mandato como prefeita em função de alguma impossibilidade do marido na ocupação de cargo político: em um dos casos, o marido já havia sido prefeito em dois mandatos seguidos, e a esposa, vereadora atuante no município, assume o desafio de candidatar-se e acaba eleita, e em outro, o marido já havia sido vice-prefeito, prefeito e não conseguiu reeleger-se, e depois de 4 anos, a esposa surge como um nome forte para candidatar-se.

"Meu pai era ligado a partido político, mas nunca exerceu cargo. Era uma liderança comunitária. Meu marido não tinha ligação nenhuma com política. Acho difícil identificar qual foi a maior influência, acho que a decisão partiu de mim, da vontade de fazer algo bom, mas em conversa com a minha família" Prefeita J. 
"Nem meu pai nem meu marido eram políticos. Pode-se dizer que a decisão partiu de mim mesma. A decisão de ser prefeita surgiu após ter sido Secretária de Saúde, vereadora mais votada e depois disso resolvi encarar - e fui eleita para dois mandatos seguidos". Prefeita $R$.

"Na minha família de origem não tínhamos nenhuma ligação política e, portanto, ali não houve nenhuma influência. A influência veio do meu marido, que já havia sido prefeito nas duas gestões passadas à minha. Eu era vereadora, muito bem votada e meu nome apareceu como opção. Fui, e gostei" Prefeita I.

"Meu pai não era ligado à política, mas meu marido foi vice-prefeito e prefeito no município, e foi um bom prefeito, e eu sempre o acompanhei bastante, como primeira dama e como presidente do partido. Depois de ele ser prefeito, meu nome começou a circular como uma possibilidade nas eleições de 2012. Eu nunca havia pensado em ser prefeita, mas o nome foi surgindo na comunidade e o partido convidou, e então, em decisão com o meu marido, aceitei!". Prefeita N.

Identificou-se que todas as prefeitas já possuíam alguma atuação política anterior a ocupação do cargo de prefeita, e pode-se dizer que papéis desempenhados anteriormente na maioria das vezes, serviram de "treinamento" para a fala pública, para a ocupação do espaço público e dos palanques, bem como para a própria gestão, as articulações eleitorais e o "corpo a corpo" com o eleitorado. Esse fato está ligado a construção do capital simbólico e do capital político proposto por Bourdieu (1980), no sentido da importância de construção de uma legitimidade quanto pessoa apta e reconhecida para agir em nome dos representados. Esses papéis anteriores foram desempenhados ou como primeira-dama, ou como secretária no município, ou como presidente de partido político no município, ou como vereadora - três haviam sido vereadoras em seus municípios.

Em relação ao fato de três delas terem ocupado cargos de vereadoras, há um destaque para a Lei das Cotas, pois essas foram convidadas a concorrerem no legislativo em função da necessidade de os partidos apresentarem os 
percentuais de $30 \%$ de candidaturas de mulheres. A decorrência disso, é que, de lideranças locais, surgiram líderes no legislativo local e posteriormente no executivo. Todas afirmaram que ações afirmativas como a Lei de Cotas são importantes para o surgimento das lideranças femininas, mesmo que num primeiro momento, possa parecer "obrigação" para a mulher candidatar-se para o preenchimento das vagas determinadas pela referida lei, aos poucos, vão-se formando lideranças femininas. A Prefeita R deixa claro que "Temos que destacar a importância da Lei das Cotas, por foi muito em função dela que eu concorri para vereadora e a partir disso construí meu nome para ser prefeita".

Existe nos discursos, um sentimento de "responsabilidade" e o reconhecimento da necessidade de honrar os votos e a confiança dos eleitores conduzindo à ideia de uma conquista, de uma importância de ter "chegado lá". O pioneirismo em relação ao papel de uma mulher à frente da prefeitura dos seus municípios também é bastante mencionado sendo que a maneira de expor a trajetória política inaugural de mulheres nos seus municípios, o que sugere algo de dimensão afirmativa da presença feminina em espaços de representação: “Fui a primeira e única prefeita, e pode-se destacar que em 2012, o meu município foi o único do estado em que teve duas mulheres concorrendo ao cargo de prefeita. Isso é inédito e importante "(Prefeita I); "Ser a primeira prefeita do município é um orgulho muito grande" (Prefeita J.);"Fui a primeira prefeita, e única, dentre todos os prefeitos em mais de 50 anos, a conquistar uma reeleição" (Prefeita N.); "Fui a primeira prefeita de toda a região das Missões, e também a única reeleita" (Prefeita R.).

As prefeitas entrevistadas demonstraram personalidades distintas, mas características bastante comuns: firmeza, alegria, apego à família, laços com a comunidade e uma preocupação bastante especial em fazer "o melhor, o bem, melhorar a vida das pessoas, contribuir para o município". Ao serem questionadas sobre quais os sentimentos que impulsionaram a entrada dessas mulheres na vida política, a comunidade aparece como o elemento mais importante para essa escolha de vida:

"Foi o sentimento de prazer de ver as coisas acontecerem por meio da atuação da gente. A vontade de ajudar a comunidade. Esse é o grande motivo, o grande sentimento que me levou a ser política e prefeita. $O$ que move a gente, faz com que tu busques, faz tentar melhorar, resolver 
e fazer melhor para a comunidade. Não é assistencialismo. É a proximidade com as pessoas e poder fazer algo pela vida das pessoas" Prefeita I.

"A comunidade. Servir a comunidade, fazer melhor. Eu quis fazer muitas coisas boas, muitas melhorias para a população. E isso me fez entrar na política e a ser prefeita. Eu sempre acreditei que pela política séria podemos mudar e melhorar uma cidade. E esse sentimento me acompanha sempre" Prefeita J.

"Foi um sentimento de dever de contribuição. Queria contribuir para o município. Pensou, junto com o marido, que já que tinham escolhido o município, e que não queriam de ali sair, então talvez ser prefeita para ajudar a comunidade e fazer algo seria uma boa missão. Só reclamar não ajuda, tem que tentar fazer algo que deixe a marca de contribuição para o município" Prefeita $N$.

"Sempre pensando em fazer algo bom para a comunidade. Isso como funcionaria pública, como vereadora, como prefeita. Eu tenho muito orgulho das conquistas, do atendimento em saúde que consigo oferecer a população, acho que isso faz diferença na vida das pessoas" Prefeita R.

Sobre a relação família $\mathrm{x}$ política, outro elemento bastante comum, a importância da família e do apoio do marido:

"A importância do meu marido é total. Aprendi fazer política com ele e ele me acompanha, nós conversamos, ele me tranquiliza. Eu o acompanhei como primeira dama, e ele agora me acompanha como marido. Minhas filhas sempre acompanharam, praticamente cresceram em meio aos compromissos políticos". Prefeita I.

"A minha família tem influência total na minha trajetória. Minha família é tudo. Afinal é de lá que a gente sai para trabalhar e para lá que a gente volta, então não tem como não considerar a família como a base de tudo que a gente vai fazer. A minha família sempre foi central nas 
minhas decisões e meu marido é um apoio importante". Prefeita J.

"Teve muita influência do marido, e as filhas apoiam muito. Meu marido me acompanha nos compromissos, conversamos muito sobre tudo. Tem muito apoio da família, embora eu acho que a família é o que fica mais de lado, mais sem atenção, por mais que a gente tente dar atenção sempre que possível." Prefeita N.

"Meu marido sempre me apoiou e isso para mim é fundamental e muito importante. Ele não gosta de política, mas sempre esteve comigo, e minhas filhas se criaram no meio da política, ou em campanha, ou com a mãe secretária municipal, ou vereadora, ora como prefeita, enfim, isso realmente faz parte da rotina da família". Prefeita R.

Chamou atenção, o fato de que em suas falas, as prefeitas constantemente pareciam reforçar certos estereótipos femininos como sensibilidade, aspectos de vaidade e um "jeitinho feminino". A utilização dos chamados "atributos femininos" no campo político tem adquirido significados diferentes, podendo pode significar barreiras, mas também, dependendo da situação, remeter a uma capacidade e interesse de quem os utiliza, agregando sentidos positivos, valorizando uma candidatura e compondo parte do capital simbólico de uma personalidade pública. Segundo a Prefeita J “a mulher já tem essa sensibilidade que já vem da natureza". Para a Prefeita I, "o fato de ser mulher facilita esse contato com o povo". A Prefeita N diz que "talvez por ser mulher, e por ser mais sensível, os ataques não são tão fortes".

Outro destaque bastante importante sobre os atributos femininos, foi identificado especialmente nos entendimentos sobre a vaidade feminina, sobre a importância da apresentação: "Ah, a mulher tem a questão da unha, do cabelo, da maquiagem e o homem não tem. A gente tem que se arrumar um pouquinho" (Prefeita I.); "Às vezes minha filha diz: mãe, vamos arrumar esse cabelo. Aí vou para o salão de beleza com ela e já temos um momento juntas, mãe e filha" (Prefeita J.). Ainda, é possível reconhecer novamente, alguns elementos da abordagem sobre o capital político (BORDIEU, 1980; 1996) e sobre o desafio de conexão entre grupo e indivíduo representante (BORDIEU, 1986) sobre as técnicas a serem utilizadas por um líder ao relacionar-se com os liderados, quando a Prefeita R. fala sobre a importância de manter uma boa 
aparência e sobre como ela deve saber dirigir-se a diferentes grupos em diferentes espaços:

"Eu reservo um tempinho rápido no salão para manter o jeito feminino. Nada de exagero, mas um pouco para me arrumar, para estar bem apresentada. Meu salto fica aqui no gabinete, eu trabalho de salto alto sempre. Mas, se vou para uma obra, coloco uma botina. Então eu sempre cuido disso: saber onde está e estar adaptada ao espaço e ao público". Prefeita R.

O papel duplo, mesmo na vida pública, mencionado pela Prefeita I. chama atenção e vale destaque:

"Existe o papel político da mulher e o papel social da mulher. Uma prefeita tem esses dois. Um homem, o papel político é mais marcante. Como eu fui primeira dama antes de ser prefeita, isso para mim é muito claro. Mas para as pessoas não. Para a comunidade, eu sou a mesma pessoa. Eu tento ir a tudo, participar de tudo: apresentações nas escolas, clube de mães, datas comemorativas, tudo. Mas confesso que as vezes não consigo estar presente, é muita coisa. Eu tento conversar e explicar que vou conseguir participar de tudo. Então o papel político para mim é o papel de prefeita, de gestora, de administradora. E o papel social é aquele de estar presente, estar junto com as pessoas". Prefeita I.

Assim, está claro que a prefeita possui mais esse desafio: de conciliação do papel social que no caso de prefeito pode ser tranquilamente desempenhado pela primeira-dama, e do papel político e administrativo que a função requer. Assim a presença da mulher em cargos públicos traz outros significados, que, por vezes, podem parecer excludentes, mas têm sido utilizados como valores complementares na construção de identidades políticas estratégicas das mulheres. O papel privado de boa mãe e esposa não é oposto à competência administrativa ou ao compromisso com a coisa pública. Pelo contrário, tem sido muitas vezes, apresentado como evidência da capacidade de gestão.

Ressaltam que a prefeita tem uma rotina que não pode deixar de desdobrar-se entre casa e prefeitura, ou seja, uma relação entre o público e o privado. Em várias falas, as prefeitas fizeram referência ao trabalho doméstico, e à educação 
dos filhos: "Eu tenho ajuda de duas funcionárias em casa que coordenam limpeza, roupa, comida, mesmo assim sempre tem algo em casa que sobra para a mulher, a jantinha da noite, por exemplo". (Prefeita I.). Ainda:

"Eu levanto muito cedo, sou a primeira a chegar e a última a sair. Eu sempre anoto tudo que vou fazer no dia, e tento ir em tudo, tudo mesmo que me convidam. E sempre tento levar meu marido comigo. As minhas filhas já não estão todo o dia comigo, então as tarefas da casa são mais das minhas coisas e do meu marido. Mas a casa também faz parte da rotina e preocupação da gente" Prefeita N.

"Eu tenho uma assessoria de uma funcionária em casa, e minha filha maior também ajuda, principalmente quando ela está de férias. A casa não para, sempre tem algo para fazer. No meu dia-a-dia eu preciso levar e buscar minha filha pequena na escolinha, e sempre tem uma tarefinha, um teminha, algo para ajudar a pequena". Prefeita J.

"Eu tenho duas meninas, e até pouco tempo eu tinha uma assessoria doméstica. Então eu me dei conta que para ensinar minhas filhas a ter uma responsabilidade com a casa, a melhor forma era eu assumir isso e dividir a tarefa com a família. Eu dispensei a minha funcionária doméstica para tentar formar minhas filhas com a responsabilidade de todos ajudarem na casa. Essa foi a maneira que eu encontrei para garantir essa responsabilidade às minhas filhas. Hoje, as tarefas da casa são comigo e com as minhas filhas. As minhas filhas são meu orgulho, estudam bastante, tem notas ótimas e me ajudam em casa." Prefeita R.

Toda e qualquer experiência, seja em esfera pública ou privada, é permeada por aspectos positivos e negativos, e reconhecer as recompensas, dificuldades e aprendizados faz parte de um crescimento que agrega valor à carreira e liderança. No caso da vivência como prefeita isso é muito marcante, sendo que cada entrevistada pode identificar esses elementos em suas atuações.

As recompensas mencionadas sobre ser prefeita, transitam entre as realizações da gestão, o sentimento que as pessoas a elas destinam e o orgulho de ser a mulher à frente da prefeitura de seus municípios. Para àquelas classificadas como Prefeita Esposa, além das realizações da gestão, há uma ênfase significativa ao sentimento que as pessoas a ela destinam: "A admiração, o 
reconhecimento e o carinho das pessoas" (Prefeita I.) e "A dedicação reconhecida" (Prefeita N.), isso combinado com o grande orgulho, identificado em suas falas, de ser uma mulher à frente da prefeitura. Já para as classificadas como Prefeita por Iniciativa Própria têm em comum um destaque para as realizações do governo, não as reconhecendo, necessariamente uma relação com o fato de ser mulher:

"As minhas recompensas são as coisas que eu consegui construir, comprar, melhorar para a cidade. As obras, os asfaltamentos, as máquinas, os carros e implementos agrícolas. Uma coisa que me faz feliz é a ajuda que pude dar aos agricultores com os maquinários adquiridos. Essas recompensas estão bem ligadas à gestão, e não ao fato de ser mulher, acho que estão na dimensão da gestora pública. Enfim, a maior recompensa, com certeza é o serviço à comunidade." Prefeita J.

"Eu tinha muita preocupação com as pessoas indo embora do município, então tentamos fortalecer o agricultor. Uma grande recompensa foi ver o fortalecimento da economia do município por meio de ações voltadas para o agricultor. Incentivamos a atividade da suinocultura, trabalhamos as estradas para dar trafegabilidade ao agricultor, adquirimos máquinas para facilitar, por meio de ações cooperadas, o dia-a-dia dos agricultores do município. Outra recompensa é a instalação de atendimento em clínica médica. Eu sou muito orgulhosa do atendimento de saúde que o município presta aos moradores". Prefeita R.

As dificuldades destacadas foram:

"Pode-se destacar duas coisas como dificuldade em ser prefeita: a burocracia e o desmerecimento das pessoas. A burocracia é terrível, faz uma demora para as coisas acontecerem. A gente quer ver tudo pronto, novo, construído, mas muito emperra na burocracia. Às vezes por um mínimo detalhe no processo, algo como algum documento específico, temos que parar uma obra importante". Prefeita I.

"As dificuldades têm origem na falta de recursos e na grande burocracia exigida para tudo que se faz na prefeitura. Muitas vezes a gente faz um planejamento e quando recebe o recurso vem bem menos 
que o esperado, e isso para um município pequeno é muito difícil, pois não conseguimos cumprir o planejado por falta de recursos." Prefeita J.

"As dificuldades é que a gente não consegue realizar tudo que quer. A gente quer sempre fazer mais, e realizar tudo que a gente sonha antes de assumir a prefeitura, mas não tem recurso suficiente, tem as normas que devem ser seguidas à risca e isso muitas vezes deixa a gente mais limitada". Prefeita N.

"A ingratidão das pessoas. Isso me magoa. Eu sempre tento ajudar tanto, e tem tantos casos em que as pessoas não reconhecem, não valorizam. Mas acho que isso não tem relação com o fato de eu ser mulher, mas como o fato de que as pessoas querem sempre mais e não se colocam no lugar do outro. Eu não acho que por eu ser mulher, mas pelo que as pessoas esperam mesmo". Prefeita R.

Ao serem questionadas sobre a relação das dificuldades com o fato de serem mulheres, a Prefeita J. foi aquela que destacou com maior ênfase:

"Acho que nenhuma recompensa tem relação com ser mulher, mas muitas dificuldades têm relação com o fato de ser mulher. Durante todo o mandato eu sentia no dia-a-dia que muitos homens não se sentiam confortáveis pelo fato de ter uma mulher na prefeitura. Eu sentia que muitos achavam que por ser mulher a autoridade não era a mesma. Eu realmente senti isso, já na campanha, e durante os anos como prefeita".

Sobre a trajetória política, se estão satisfeitas e se mudariam algo se pudessem "voltar atrás", as prefeitas mostram-se bastante satisfeitas: "Estou muito satisfeita. Eu faria tudo novamente. Acho que só me arrependo do que deixei de fazer, mas do que eu fiz, eu gosto e estou satisfeita." (Prefeita N) "; "Eu faria tudo de novo. Valeu a pena"! (Prefeita R.). As que considerações sobre alguma conduta diferente ao longo da atuação como prefeita foram bastante específicas sobre as suas relações com a equipe de colaboradores:

"Eu estou satisfeita e feliz. Mas se eu pudesse voltar atrás talvez eu cobraria mais dos funcionários. Às vezes, pelo fato de ser funcionário público, alguns se acomodam, e eu não acho junto pois todos tem que trabalhar da melhor forma possível, afinal todos recebem seu salário no 
final do mês. E outra coisa: eu não gostaria que ninguém carregasse esse estigma de funcionário público, gostaria que todos trabalhassem bem e felizes. Mas eu estou feliz com o que fiz, com os recursos que trouxemos, com o apoio da comunidade e com o respeito dos funcionários". Prefeita I.

"De forma geral eu estou satisfeita. Fiz tudo com honestidade, com as melhores intenções. Eu tinha muitos planos e sonhos para o município. Em relação a voltar atrás, hoje eu me acho mais preparada para montar uma equipe qualificada, leal e de confiança, que esteja alinhada com o que eu gostaria de fazer. Acho que a equipe de funcionários públicos, seja do quadro efetivo ou dos cargos comissionados tem um papel fundamental no sucesso da gestão". Prefeita J.

Ao serem questionadas sobre o aprendizado adquirido, nas falas das prefeitas foi possível observar duas menções principais: questões ligadas a gestão pública e outras ligadas ao aprendizado pessoal: "Aprende a buscar soluções, a se relacionar com outros municípios, aprende a buscar recursos, a pensar na comunidade. Aprende também a conviver com a burocracia, com a lentidão dos processos". (Prefeita I.); "Aprendi muito. Sobre gestão pública, sobre gestão de equipe. E quero continuar estudando, quero voltar aos estudos sobre essa e outras temáticas. $\mathrm{O}$ dia a dia no setor público ensina muito. A equipe influencia muito". (Prefeita J.) "Aprendi a compreender as pessoas." (Prefeita N.); "Aprendi a ter mais equilíbrio emocional. Eu aprendi que não adianta ter ansiedade que eu não vou conseguir resolver todos os problemas do meu município. Tudo ao seu tempo". (Prefeita R.).

Embora, no instrumento de pesquisa não tenha se destacado nenhuma questão em relação ao machismo, esse foi um aspecto bastante mencionado pelas prefeitas, em especial para as duas classificadas como Prefeitas por Iniciativa Própria:

"Na campanha muitos diziam que eu não tinha chance porque eu era mulher. A nossa sociedade é machista, uma cidade pequena, de interior, e não podemos dizer que não sofremos com o machismo. Tem sim. Mas eu quero ver onde está escrito que a mulher tem que ficar em casa cuidando da casa e dos filhos, e que o homem tem que assumir 
cargos públicos. Quem disse isso?". Prefeita J.

"A campanha foi bem difícil, o tempo todo eu ouvia que eu não tinha capacidade, que era mulher, e teve até música da oposição rodando em carro de som que abordava que lugar de mulher não é na prefeitura. Teve uma coisa muito machista, era feio ouvir aquilo. Mas acho que foi aí mesmo que as mulheres se revoltaram e votaram em mim, acho que deu o efeito contrário". Prefeita R.

Outro elemento importante, ainda em relação ao machismo, é que apesar de já possuírem certa experiência política, aparece o receio de serem atacadas em suas vidas privadas, sendo presente em suas falas a "necessidade de se resguardar, ter retidão e postura". Esse aspecto foi fortemente mencionado em especial para as Prefeitas por Iniciativa Própria, mais do que as Prefeitas Esposa, ilustrado pelo fato de surgimento de alguns comentários maldosos em que pessoas da comunidade abordavam os maridos, com tons maliciosos, o que apareceu nas suas angústias:

"Algumas vezes chegavam a falar para o meu marido: 'a tua mulher chegou sozinha com o fulano na reunião, chegaram os dois no mesmo carro, e só os dois - mas o fulano era secretário na prefeitura. Às vezes falavam sobre eu chegar ou sair sozinha dos lugares, com intenção de deixar algo subentendido... $O$ machismo também está nesses comentários maldosos". Prefeita J.

"É difícil porque tu tens que ir a muitos lugares e o teu marido não está sempre contigo, pois ele tem o trabalho dele, e aí algumas pessoas acabam usando isso para te difamar. A forma como encontrei para evitar um pouco isso é deslocar um parente que era funcionário da prefeitura para ser meu motorista e me acompanhar. Mesmo assim falavam. A minha resposta para isso sempre foi: mas e daí? Isso não é função da prefeita, estar em lugares, acompanhar obras e participar de reuniões e eventos no município?" Prefeita $\mathrm{R}$.

Por último, um aspecto bastante importante e colocado pelas prefeitas em suas falas foi a relação da eleitora mulher com a candidata mulher, e até mesmo dos eleitores de forma geral com uma prefeita mulher. De forma geral, essas prefeitas acreditam que o baixo número de mulheres, tanto no poder executivo 
como no legislativo das prefeituras diz respeito ao fato de as próprias mulheres não reconhecerem as mulheres como uma boa opção como autoridade. Esse argumento foi colocado no sentido de que a maioria da população é de mulheres, então, se as eleitoras mulheres reconhecem as próprias mulheres, teríamos muito mais representantes femininas na política: "Se as mulheres acreditassem nas mulheres, teríamos muito mais mulheres eleitas. Às vezes eu sinto que o respeito e a confiança por um homem são diferentes" (Prefeita I.), "Se a gente for analisar, as mulheres não valorizam as mulheres. Olhe os votos. A maioria dos eleitores são mulheres, e quantas prefeitas e vereadoras temos? As mulheres acham que os homens são mais capazes" (Prefeita J.). Essa fala das prefeitas sobre a valorização do homem vai ao encontro de BOURDIEU (2011), quando o autor trabalha a naturalização das diferenças, quando se apresentam como esquemas de pensamento. E isso obviamente, segundo a fala das prefeitas, não é construção apenas masculina, mas também feminina.

Assim, as relações entre o masculino $x$ feminino não deixa de estar presente nos discursos e nas atuações dessas prefeitas. Preocupações com imagem, com os vários papéis a serem desempenhados, com a qualidade da gestão, e até mesmo a relação com o próprio eleitorado feminino permeia a vida dessas mulheres prefeitas.

\section{CONSIDERAÇÕES FINAIS}

As mudanças políticas e culturais, mesmo que consideradas sem grandes aprofundamentos, trazem uma percepção de é possível considerar uma tendência, de inserção das mulheres nas disputas eleitorais brasileiras. A Lei 9504/97, conhecida como "Lei das Cotas", estabelece um percentual mínimo de $30 \%$ de candidaturas femininas nas das coligações, parecendo ser um mecanismo afirmativo de inserção das mulheres na política. Embora ainda haja críticas sobre sua efetividade, considerar-se que, mesmo que de forma lenta e gradual, esse instrumento legislativo passa a ser uma ação afirmativa para as mulheres.

Por outro lado, ao observar alguns dados quantitativos sobre participação política feminina, é possível encontrar indícios sobre mecanismos de dominação que mantém a baixa participação das mulheres nas instâncias representativas da política e do poder. $O$ fato de a população ser de maioria feminina, e os 
cargos políticos serem majoritariamente ocupados por homens é um fenômeno que oferece muitas possibilidades de análise. Isso foi veementemente abordado pelas prefeitas. Ao tentar interpretar esse fenômeno, junto às prefeitas entrevistadas, elas parecem descrever uma abordagem reducionista, mesmo que não conformadas com isso, sobre a tradição e a facilidade da dominação masculina, sobre a maior capacidade masculina de atuar na política, que entende a mulher como desinteressada, menos capaz e menos envolvida nos assuntos públicos e de gestão política. Constatado esse fato, é necessário buscar as causas, os porquês desse entendimento, e quais as formas de superar essa visão de dominação. Nesse sentido, esse estudo coloca-se como um passo no sentido de buscar a realidade dessas mulheres prefeitas, e com essas vivências, entender as suas particularidades, seus desafios, aprendizados e superações nessa carreira, tradicionalmente ocupadas por homens.

Embora as prefeitas apresentem personalidades e histórias bastante distintas, foi possível identificar alguns pontos comuns nas suas falas enquanto mulheres que se tornaram prefeitas: a preocupação com a comunidade e com o fazer o bem para as pessoas, o apego a família e a importância do apoio de marido e filhos nas suas carreiras e o orgulho diante do pioneirismo no papel de prefeita nos seus municípios.

As prefeitas de fato, dividem-se no seu papel público e privado, e se por vezes, podem parecer excludentes, muitas vezes têm sido utilizados como valores complementares na construção de identidades políticas estratégicas das mulheres. Assim, a presença da mulher nos espaços públicos traz novos significados tanto para a política como para as mulheres, já que o papel privado de mãe e esposa dedicada não é, necessariamente, oposto à competência administrativa, ao compromisso com a gestão pública e com a firmeza necessária para atuar como chefe do executivo municipal. Pelo contrário, tem sido muitas vezes, apresentado como mérito, como demonstrativo da capacidade feminina de gestão.

Constatados os fatos, é necessário buscar causas, novos conhecimentos e maiores entendimentos. Conhecer os desafios femininos faz-se muito importante para a superação de barreiras, de preconceitos e de quebras de estereótipos sobre o feminino $\mathrm{x}$ masculino, sobre os papéis previamente determinados sobre capacidades, ocupações e realizações. Esse é o desafio lançado nesse estudo e que não se esgota nele mesmo. Novos estudos fazem-se necessários, buscando-se pesquisas com um número maior de mulheres 
prefeitas.

\section{BIBLIOGRAFIA}

Alves, J. (2007). Paradoxos da participação política da mulher no Brasil. Disponível em http://www.prt18.mpt.gov.br/eventos/2007/mulher/anais/ artigos/joseeustaquio.pdf Acessado em 20/11/2016.

Barbosa, C. (2010). Atuação das Mulheres na Política Local: Ranços e Avanços. Revista Ágora, Vitória, n.11, p.1-27.

Barbosa, C.; Cavalcanti, V. (2010). Um Olhar sobre a Trajetória das Prefeitas Baianas: Entraves e Avanços. Fazendo Gênero 9. Diásporas, Diversidades, Deslocamentos 23 a 26 de agosto de 2010. Disponível em: http://www.fazendogenero.ufsc.br/9/resources/anais/1277462300ARQUIVOF azendoGenero.pdf. Acesso em 20 de novembro de 2016.

Blay, E. (2002). Mulher e igualdade: cidadania e gênero. Social Democracia Brasileira, Brasília, v.1, n.2, pp. 58-63, mar.

Blay, E. (2015.) As prefeitas. Rio de Janeiro: Avenir Editora.

Botelho, L. et al. (2006). Percepções sobre o papel da mulher na sociedade do conhecimento. In: Seminário Internacional Fazendo Gênero VII, 2006, Florianópolis. Anais Seminário Internacional Fazendo Gênero VII.

Botelho, L. (2008). Ascensão Profissional Feminina em Organizações Baseadas em Conhecimento. Universidade Federal de Santa Catarina. Dissertação (Programa de Pós-Graduação em Engenharia e Gestão do Conhecimento) - Universidade Federal de Santa Catarina, Florianópolis.

Bourdieu, P. (1980). O senso prático. Petrópolis: Vozes.

Bourdieu, P. (1986). A representação política. Elementos para uma teoria do campo político. In: Bourdieu, P. O poder simbólico. Lisboa: Difel.

Bourdieu, P. (1996). Razões práticas: sobre a teoria da ação. Campinas, SP: Papirus.

Bourdieu, P. (2011). A dominação masculina. Rio de Janeiro: Bertrand Brasil.

Brabo, T. (2003). Gênero e poder local: eleições municipais do ano 2000 em Marília (SP). Tese (Doutorado em Sociologia), São Paulo: Departamento de Sociologia, Universidade de São Paulo.

Bruschini, C.; Lombardi, M. R.; Mercado, C. M.; Ricold, A. (2011). Trabalho, renda e políticas sociais: avanços e desafios. In: Barsted, L. L.; Pitanguy, J. (orgs.). O Progresso das Mulheres no Brasil 2003-2010. Rio de Janeiro: Cepia, Brasília: ONU Mulheres. 
Bruschini, C. (2000). Gênero e trabalho no Brasil: novas conquistas ou persistência da discriminação? (Brasil, 1985-1995). In: Rocha, M. I. B. da (org.) Trabalho e gênero: mudanças, permanências e desafios. São Paulo: Editora 34. p. 13-58.

Fletcher, J. K. (2006). Gender perspectives on work and personal life research. Disponível em: www.popcenter.umd.edu/events/nichd/papers/fletcher.pdf

Fournier, V; Smith, W. (2006) Scripting Masculinity. Ephemera Theory \& Politics in Organization. Vol. 6 no.2. p.141-162.

Gil, A. (1991). Como elaborar projetos de pesquisa. São Paulo: Atlas.

Hughes, J. (1980). A filosofia da pesquisa social. Rio de Janeiro: Zahar.

Loden, M. (1988). Liderança feminina: como ter sucesso nos negócios sendo você mesma. São Bernardo do Campo, SP: Bandeirante.

Miles, M.; Huberman, M. (1994). Qualitative Data Analysis. Thousand Oaks: Sage.

Minayo, M. C. S. et al. (1994). Pesquisa social: teoria, método e criatividade. Petrópolis: Vozes.

Moraes, F. C.V. (2004) Diversidade e Inclusão: a força de trabalho feminina na Philips do Brasil. Trabalho apresentado a Fundação Dom Cabral para a conclusão do curso Gestão Responsável para a Sustentabilidade. São Paulo.

Moraes, L. (2008). A trajetória de mulheres executivas em universidades catarinenses. (Tese de Doutorado) Programa de Pós-Graduação em Engenharia de Produção) Universidade Federal de Santa Catarina.

Rabay, G. et al. (2013). As Prefeitas Paraibanas de 2013 de 2016. Seminário Internacional Fazendo Gênero 10 (Anais Eletrônicos). Florianópolis.

Rodrigues, D. (2016). As prefeitas em perspectiva: representatividade Feminina na política paraibana. Revista Eletrônica de Ciência Política, vol. 7, n. 1.

Roesch, S. M. A. (1996). Projetos de estágio do curso de administração: guia para pesquisas, projetos, estágios e trabalhos de conclusão de curso. São Paulo: Atlas.

Saffioti, H. (1976). A Mulher na Sociedade de Classes. Rio de Janeiro: Editora Vozes.

Seidman, I. (1998). Interviewing as qualitative research: A guide for researchers in education and the social sciences (2nd ed.). New York: Teachers College Press.

Souza, P. F. de; Siqueira, E. S.; Binotto, E. Liderança Feminina na Gestão Pública: Um estudo de caso da Universidade do Estado do Rio Grande do Norte. Disponível em: http://www.abepro.org.br/biblioteca/enegep2011 TNSTP14189318429.pdf . Acesso em 20 de setembro de 2016

TER-RS - Tribunal Regional Eleitoral do Rio Grande do Sul. Eleições 2012: Divulgação dos Resultados. Disponível em http://www.trers.jus.br/eleicoes/2012/1turno/ RS87483.html. Acesso em 20 de setembro de 2016. 
Liderança feminina na gestão pública municipal - desafios e aprendizados de mulheres prefeitas

TSE - Tribunal Superior Eleitoral. Disponível em http://www.tse.jus.br/. Acesso em 20 de setembro de 2016.

Vaz, G. (2008). A participação da mulher na política brasileira: a lei de cotas. Monografia apresentada para o curso de Especialização em Processo Legislativo. Câmara dos Deputados. 